\title{
Mujeres inmigrantes en el estado español; su sobrevivencia en la frontera de la ciudadanía
}

\author{
Paki Venegas*
}

\begin{abstract}
Para las mujeres inmigrantes yo tengo el sueño de que todas tuviésemos la oportunidad de realizarnos como personas y como mujeres.
\end{abstract}

Rosana, inmigrante argentina

Los movimientos migratorios actuales se caracterizan por una importante presencia de mujeres. Los cambios en la situación familiar y la movilidad y flexibilidad del mercado de trabajo han creado una demanda laboral que está siendo cubierta por el colectivo femenino. El presente artículo pretende aproximarse al proyecto migratorio de las mujeres extranjeras que residen en España y ahondar en los principales problemas que encuentran en la sociedad de acogida, tanto en el ámbito laboral como en la regulación de su situación administrativa, en la búsqueda de vivienda, y en su adaptación afectiva y cultural.

Es evidente que la sociedad española está configurada por un mestizaje de gentes y una mezcla de culturas. Este hecho que no es nuevo, sino que ha existido siempre, se ha visto reforzado en los últimos decenios por el auge de la emigración de los países empobrecidos a los países ricos. ${ }^{1}$ Así, aunque hasta hace relativamente poco tiempo el estado español se situaba entre los países emisores de población emigrante, ${ }^{2}$ desde los años ochenta han descendido estos flujos de emigración y ha aumentado la entrada de extranjeros procedentes, en su mayoría, de países con graves problemas económicos.

Por otro lado, los movimientos migratorios actuales se caracterizan, entre otras cosas, por una importante presencia de mujeres. ${ }^{3}$ Los

* Universidad Autónoma Metropolitana (UAM), Unidad Xochimilco. Correo electrónico: lua_lila@hotmail.com.

${ }^{1}$ En este sentido, las migraciones actuales no pueden entenderse sin hacer referencia, en el contexto de un mundo globalizado, a los problemas estructurales marcados por las relaciones de desigualdad y la dominación de los países del Norte sobre los del Sur, relaciones que ocasionan el avance de la pobreza y la exclusión social en los países empobrecidos.

${ }^{2}$ Aún hoy residen más de dos millones de españoles fuera del territorio del estado (García, 2000).

${ }^{3}$ Carrasquilla y Pellicer (2004) mencionan otras tendencias que caracterizan a las

ESTUDIOS DEMOGRÁFICOS Y URBANOS, VOL. 21, NÚM. 2 (62), PP. 473-487 
cambios en la situación familiar, junto con la movilidad y flexibilidad del mercado de trabajo, han creado ciertas demandas laborales que están siendo cubiertas por el colectivo femenino. El presente artículo pretende ser una aproximación al proyecto migratorio de mujeres extranjeras residentes en el estado español, entendiéndolas y ahondando en los principales problemas que han encontrado en la sociedad de acogida. ${ }^{4}$ En este sentido se pretende responder a preguntas como ¿por qué las mujeres no se consideran sujetos con proyectos migratorios propios?, ¿por qué cuando se reconocen se les vincula frecuentemente a las migraciones masculinas?, ¿qué obstáculos encuentran en su proyecto migratorio? Finalmente es necesario advertir que a pesar de que en este artículo a veces se habla de las mujeres inmigrantes como un todo homogéneo, se trata de un colectivo diverso, dinámico y diferente según su sociedad de origen y su propia historia de vida, y todo ello marca las alegrías, los conflictos, las decepciones, los logros y las estrategias de supervivencia de cada mujer.

\section{Las cifras y los patrones migratorios}

En el año 2002 había en el estado español 1324001 extranjeros $^{5}$ con tarjeta o permiso de residencia en vigor, de ellos $44.79 \%$ eran mujeres y $55.21 \%$ hombres, es decir, 590629 mujeres extranjeras tenían permiso de residencia en vigor, frente a 738019 hombres (MIR, 2002).

Los colectivos de población extranjera con mayor número de mujeres al finalizar el año 2002 eran: la República Dominicana, con

migraciones actuales: la globalización, que contribuye a la posibilidad de movilidad y flexibilidad de los factores productivos, entre ellos la mano de obra; la diversificación de los flujos de migración actuales, así encontramos refugiadas/os de guerra, asiladas/ os políticos, mano de obra barata, trabajadoras/es altamente calificados, etc., y la aceleración en el volumen de migrantes, el cual se ha visto multiplicado en las últimas décadas.

${ }^{4}$ Los datos de este artículo provienen de la investigación etnográfica que realizó la autora para elaborar el material didáctico "Voces de mujeres inmigrantes: la educación intercultural desde una perspectiva de género". Esta investigación se basó en la consulta de fuentes de datos secundarios: publicaciones periódicas, prensa y rastreo bibliográfico de material que abarcaba esta temática, y el análisis de la información obtenida de un total de 24 entrevistas en profundidad realizadas a mujeres inmigrantes, con y sin documentación en regla, procedentes de diversos países y residentes en las ciudades españolas de Granada y Jerez de la Frontera.

${ }^{5} \mathrm{~A}$ esta cifra hay que añadir un número no determinado de personas indocumentadas, es decir, personas que no cuentan con el permiso de residencia en el país y cuyo número, al no estar censadas, no se conoce de manera fiable. 
$67.97 \%$ de mujeres; seguida de Filipinas, con 60.15\%; Cuba, con $58.58 \%$, y Perú, con 57.92\%. En el caso de los nacionales de Ecuador, Reino Unido, Alemania, Francia, Argentina y Países Bajos, la proporción de hombres y mujeres se encontraba equilibrada (MIR). Por otro lado, el estado español se sitúa entre los que poseen proporciones más altas de migración femenina de la Unión Europea (Carrasquilla y Pellicer, 2004).

No obstante, resulta muy significativo que a pesar de estos datos hasta hace relativamente poco tiempo se hablase de una inmigración preponderantemente masculina, aun cuando existían signos claros de que se equiparaban las tasas de inmigración masculina y femenina, o que se atribuyera este aumento del número de mujeres inmigrantes al incremento de las reagrupaciones familiares, hecho desmentido por las investigaciones que se han realizado al respecto ${ }^{6}$ Conforme a este enfoque se opaca y se minimiza ${ }^{7}$ el papel de las mujeres como agentes sociales, dueñas y protagonistas de su propio proyecto migratorio. En este sentido Dolores Juliano refiere que históricamente las migraciones femeninas han sido consideradas algo excepcional y han operado sobre ellas restricciones y discursos ilegitimadores, excepto en los casos en que se encaminaban al mantenimiento de la cohesión familiar. Las mujeres como transmisoras y portadoras de la cultura serían las cariátides del templo sobre las que se sostiene la reproducción de la vida y de la cultura, y como tales cariátides se les percibe inmóviles dentro de su rol. La idea de la inmigración femenina como dependiente de la masculina se apoya por tanto en un estereotipo muy consolidado, según el cual el hombre es más móvil geográficamente. Sin embargo esta autora lo refuta arguyendo que la inmensa mayoría de nuestras sociedades son patrilocales, lo que implica que es la mujer quien abandona su hogar de origen para ir a vivir a la casa de su marido. Así, mientras el hombre podía pasar toda la vida en su grupo familiar, la mujer era inmigrante por definición, puesto que al casarse debía cambiar de lugar. Por todo ello, expone Juliano, se puede hablar de mujeres estructuralmente viajeras en contraposición

${ }^{6}$ Algunos estudios muy interesantes realizados en el estado español, como el de Carmen Gregorio, sobre mujeres dominicanas, o el de Angels Escrivá, sobre mujeres filipinas, aseguran que en la mayoría de los casos las mujeres inmigrantes no vienen por reagrupación familiar, sino que ellas mismas son las pioneras de una inmigración que posteriormente puede terminar o no arrastrando a los hombres de su familia (Juliano, 2000).

${ }^{7}$ Todo esto demuestra que los procesos migratorios no son ajenos a la discriminación de género vigente en la sociedad actual, que adjudica un papel pasivo a las mujeres, un papel estereotipado que conforme a los datos existentes en nada se asemeja a la realidad. 
a la imagen estereotipada de mujeres accidentalmente viajeras. Sin embargo, en la mayoría de los casos esta movilidad espacial resulta imperceptible (Juliano, 2000) ${ }^{8}$

La feminización de los flujos se ha convertido, por tanto, en uno de los rasgos característicos de los movimientos migratorios de hoy. Cada vez más mujeres de Asia, África, América Latina y Europa del Este se ven obligadas a emigrar hacia países ricos, buscando las alternativas y las posibilidades que su propio país no les ofrece..$^{9}$ La situación de pobreza y de marginación en que viven inmersas se ha convertido en una de las causas de emigración; no obstante, las que se van no son como se cree las más pobres de sus países, pues éstas ni siquiera tienen recursos para pagarse el viaje (Zabala, 2004). En el análisis de estos flujos migratorios se ha podido observar también un cambio en las características de esta inmigración, que pasó de obedecer casi exclusivamente a motivos de reagrupación familiar, en los años cincuenta a setenta, a una creciente migración femenina autónoma en los últimos años.

Este cambio de patrones migratorios no es homogéneo, ya que las mujeres emigran por razones diferentes. El Colectivo IOE, en un estudio realizado sobre los procesos migratorios de mujeres de distintos países, distingue al menos las siguientes modalidades en estos procesos: mujeres que emigran para asegurar la subsistencia del grupo familiar y especialmente la mejora social de sus hijos/as; mujeres solteras que emigran buscando una promoción personal además de apoyar a la familia de origen; mujeres jóvenes que emigran "por espíritu aventurero"; mujeres que salen de su país de origen siguiendo a su marido en su proyecto migratorio, y finalmente mujeres jóvenes ("segunda generación”) que llegan al estado español para reunirse con sus familiares ya emigrados (Colectivo IOE, 1998: 21-23). De todas estas modalidades, según refiere este colectivo, se puede percibir un auge de las

${ }^{8}$ Este dato es muy importante pues muchas de las inmigrantes ya han realizado una primera migración por razones estrictas de género, por ejemplo por matrimonio, y tienen por tanto más experiencia de la que se piensa en materia de integración en otra sociedad (Zabala, 2004).

${ }^{9}$ En este sentido asegura Dolores Juliano (2000) que existen determinantes económicos en la emigración que influyen de manera diferente según el género. La demanda del servicio doméstico en Europa supone un elemento de atracción de mano de obra femenina. Cabe además recordar la situación en que viven estas mujeres en las áreas rurales de su país de origen, donde el acceso a la propiedad de la tierra está fundamentalmente en manos masculinas, lo cual puede llevar a las mujeres que no tienen una inserción familiar clara a que decidan emigrar. Se producen así, según esta autora, procesos específicos de expulsión y procesos específicos de demanda que influyen en una selección de la inmigración por género. 
que emigran en forma autónoma, dejando atrás su núcleo familiar, núcleo que depende para su supervivencia de las remesas que ellas envían.

Soy enfermera pero siempre ejercí de psicopedagoga. Dirigía una escuela infantil en mi ciudad. Era una persona importante allí, estaba bien considerada y valorada pero el sueldo era muy bajo. Tuve que emigrar por problemas económicos, mi familia había contraído una deuda muy grande y con lo que ganaba en Rusia era imposible pagarla [Victoria, inmigrante rusa].

Mi familia en Senegal no vivía del todo mal, estaban dedicados al comercio. Mi padre es importante. Emigré cuando murió mi primer marido, quería algo mejor para mí y para mis hijos. La situación en mi país es mala para todos. Senegal es un país muy rico, pero es pobre y las mujeres se llevan la peor parte, tienen menos libertades [Dava, inmigrante senegalesa].

La emigración constituye en muchos casos una estrategia de supervivencia para las mujeres, sus familia y sus comunidades de origen, o una forma de liberarse de contextos opresivos para el género femenino. ${ }^{10}$ Sin embargo, paradójicamente, la discriminación de género constituye cada vez más una característica suplementaria del proyecto migratorio de estas mujeres, que escapan de un contexto opresivo y discriminatorio para insertarse en otro.

\section{La adaptación a la sociedad de acogida: el trabajo, la documentación, la vivienda y los afectos}

Las mujeres no toman al azar la decisión de emprender un proyecto migratorio sino que influyen en ella muchos condicionantes sociales,

${ }^{10}$ Begoña Zabala (2004: 3) explica que otro tipo de emigración femenina "es la constituida por mujeres con estatus desvalorizados en las sociedades de origen o con aspiraciones incompatibles con las normas tradicionales; a estas mujeres se les podría llamar refugiadas por motivos de género y serían fugitivas de matrimonios indeseados, repudiadas, prostitutas, madres solteras y víctimas o amenazadas de agresiones sexuales".

"Camerún es una sociedad donde la mujer no tiene independencia, la mujer está considerada como dependiente del marido, como si fuera de su propiedad. Primero la poligamia es legal, creo que detrás de esa posibilidad hay una idea de inferioridad, ¿cómo un hombre va a tener sólo una mujer?, por eso, a partir de la poligamia está legitimado el maltrato. En Camerún el maltrato se puede denunciar pero denunciándose tienes a toda tu familia en tu contra" (testimonio de un inmigrante de Camerún). 
económicos y personales. Las mujeres inmigrantes inician su viaje hacia los países ricos del Norte buscando nuevas estrategias de vida; es un viaje marcado por altas dosis de ilusión y, en muchos casos, por escasa información veraz sobre el lugar de llegada. Para poder realizar este viaje gastan todos sus ahorros o se embargan en préstamos de familiares y amigas/os o de las mafias, en el peor de los casos, que tardan años en pagar. A su llegada, después de todo el periplo que constituye el viaje, se encuentran con una sociedad llena de prejuicios, una sociedad que las discrimina por ser mujeres, inmigrantes y pobres, que las explota y que no las reconoce como personas con igualdad de derechos.

El viaje me lo financié con un préstamo de una amiga; yo sabía quienes me podrían conseguir el dinero, las mafias, pero yo no quería contactar con esa gente, sobre todo porque sabía que eso es meterse en hacer un pago y otro pago, es peor que un banco, porque las mafias te cobran intereses y te cobran hasta la vida misma, porque ellos te pueden llegar a traer aquí, pero no sales del prostíbulo y te digo tanto porque en México yo he conocido bastantes historias de chicas que las llevan a Estados Unidos y a otros países de Europa y las chicas se tardan 10 o 15 años en medio librarse de eso, si es que se libran... Ellas no son conscientes de lo que pasa con las mafias, creen que van a una casa a limpiar o que les van a conseguir un trabajo estable, pero en realidad las ponen de prostitutas [Laura, inmigrante mexicana].

En una ocasión un hombre se baja de su coche y me aborda para acosarme creyendo que me dedicaba a la prostitución. Me sentí pisoteada sólo por mi piel morena y mi físico, como si fuera una presa para ellos, pero me libré. A los hombres inmigrantes creo que no les ocurre esto [Eliana, inmigrante colombiana].

El mercado de trabajo al que acceden las mujeres inmigrantes se limita, en líneas generales, al servicio doméstico, la hostelería, la agricultura, el comercio en la calle y la prostitución. Estos trabajos están marcados por relaciones jerarquizadas, mal remunerados y sometidos al escaso control externo. Se trata de una relación económica en la cual se obtiene un plusvalor derivado de no pagar la Seguridad Social de la trabajadora y de abaratar los costos de producción, disminuyendo los salarios y empleando horas extra no remuneradas (UGT, 2001). ${ }^{11}$

${ }^{11} \mathrm{Al}$ respecto asegura Zabala (2004) que estos trabajos, que en muchas ocasiones rozan los márgenes de la legalidad, son apropiados para que los realicen las inmigrantes, a las que se quiere mantener en la marginalidad, ya que nunca denunciarán las condi- 
De todos esos trabajos, el servicio doméstico es el hueco laboral donde se inserta la gran mayoría de las mujeres. Esto es debido, por un lado, a que las políticas gubernamentales de regulación de flujos se han encargado de potenciar especialmente el crecimiento de esta franja ocupacional por medio del sistema de contingentes laborales para trabajadoras extranjeras ${ }^{12} y$, por otro lado, a que existe una demanda real del mismo (UGT, 2001)..$^{13}$

Dentro del servicio doméstico encontramos dos modalidades: empleada interna y empleada externa. Las empleadas internas tienen ciertas ventajas, como tener cubiertas las necesidades básicas de alojamiento y manutención, lo que les permite una mayor capacidad de ahorro. A cambio desempeñan jornadas de trabajo interminables, que llegan incluso a más de 12 horas diarias, y sobre todo, carecen de privacidad y de libertad. Todo ello conduce al auténtico enclaustramiento de muchas de ellas. Por otro lado, a las empleadas internas se les puede descontar por manutención y alojamiento un máximo de $45 \%$ del salario mínimo interprofesional, de forma que la tradición del salario en especie, que suele llegarle más a las internas (comida, estancia, etc.) sirve en la mayoría de los casos para rebajarles el salario monetario (UGT, 2001). Esto es más común en el caso de las mujeres inmigrantes que en el de las nacionales, dada su situación de desprotección y supervivencia.

Ahora trabajo con una señora mayor; le caliento la comida, le plancho su ropa... el horario es de siete de la tarde a ocho de la mañana y el sueldo es de trescientos euros. Si yo fuera española creo que me pagarían más; conozco a una señora española que trabaja cuidando ancianos y le pagan cuatrocientos ochenta euros [Marta Luz, inmigrante boliviana].

Entre las empleadas externas las cuestiones más importantes se plantean en torno a la comparación del servicio doméstico con otras

ciones de explotación debido a su situación sin papeles y sin derechos, o de precariedad por los permisos temporales de residencia y trabajo.

${ }^{12}$ En el caso de los hombres la franja ocupacional que abre el sistema de contingente es más amplia, pues pueden insertarse en trabajos relacionados con la agricultura, la construcción o el sector servicios.

Aunque son muchos los aspectos criticables en la Ley de Extranjería, destacan entre ellos el hecho de que los flujos migratorios se regulen sólo con base en que haya demanda de trabajo en áreas específicas (Zabala, 2004).

${ }^{13}$ Las mujeres inmigrantes están ocupando algunos de los espacios que dejaron las mujeres autóctonas, debido en parte a las mejoras que han experimentado respecto a sus condiciones de vida, a su acceso al mercado laboral y a sus derechos. 
actividades laborales. Así, para muchas de estas mujeres el trabajo del hogar familiar es un empleo accesible, pero a la vez muy poco valorado socialmente. La flexibilidad de los horarios que permite el trabajo en la modalidad de externa lo hace compatible con las obligaciones familiares de madre y esposa, cosa que no sucede en otros sectores donde se imponen horarios rígidos que ocupan buena parte de la jornada, y además no implica el aislamiento que supone la modalidad de interna. ${ }^{14}$ Por contraposición existe el riesgo de recibir un trato degradante o abusivo por parte de algunos empleadores, especialmente cuando se trata de inmigrantes recién llegadas o con escaso conocimiento del entorno social y del idioma (Colectivo IOE, 2001: 43).

Aquí he trabajado como interna en una casa, luego externa, luego en un bar, pero ya con mi niña pequeña sólo trabajo los fines de semana. Ahora estoy trabajando en una residencia de estudiantes pero no quieren hacerme contrato por no pagar los impuestos [Georgeta, inmigrante rusa].

Otra de las características clave en cuanto a las condiciones laborales especiales de las que trabajan en el servicio doméstico es que no tienen derecho a percibir la prestación por desempleo ni están sindicalizadas. Pueden ser despedidas cuando las/os empleadoras/es quieran prescindir de sus servicios con una indemnización de siete días de salario por año trabajado, en lugar de 45 días como está estipulado en el resto de las ocupaciones. Las pagas extra son de 15 días en vez de 30 , y en el caso de las mujeres que se encuentran en situación administrativa irregular, al no cotizar a la Seguridad Social, ante accidentes o enfermedades se encuentran completamente desprotegidas y no pueden solicitar incapacidad laboral (UGT, 2001). A todo esto hay que añadir otros problemas cotidianos que ellas enfrentan dentro de este sector y que están relacionados con la adopción de nuevas costumbres en torno a la limpieza y a la preparación de la comida, y con las dificultades de comunicación por no hablar y entender bien el idioma, como es el caso de las mujeres africanas o de Europa del Este:

En general me han tratado bien, salvo al principio en una casa donde estuve muy poco tiempo, la señora me trataba muy mal, a veces creen que somos personas atrasadas porque venimos de países pobres [Fatma, inmigrante marroquí].

${ }^{14}$ No obstante sí implica, en la mayoría de los casos, que estas mujeres enfrenten una doble y triple jornada laboral, ya que al servicio doméstico que realizan en distintas casas particulares tienen que unir el de la suya propia, con base en el cual se le evalúa como madre y esposa. 
El servicio doméstico reúne todas las características de un mercado secundario, ya que ésta definido por jornadas de trabajo interminables -sobre todo en el caso de las mujeres internas-, por no tener derecho a percibir la prestación de desempleo ni estar sindicalizadas, y por el estancamiento, ya que no es posible ascender ni dar un salto a un trabajo en mejores condiciones. A esto hay que añadir que como se trata de un trabajo que suelen realizar las mujeres, está socialmente devaluado e inadvertido, lo cual demuestra el androcentrismo existente en el ámbito laboral.

No obstante, a pesar de la precariedad del trabajo que se les ofrece, el acceso a una oferta de empleo ha sido desde 1985 hasta diciembre de 2003 su única manera de obtener una autorización administrativa para residir y trabajar legalmente en España. Este hecho ha provocado en muchos casos situaciones límite para conseguir o conservar un empleo. El valor de la persona empleada se mide en función de su producción, de ahí que la enfermedad ponga en peligro dicha relación, debilitándola e incluso rompiéndola. La enfermedad supone dejar de producir, y en consecuencia, las jefas se molestan cuando las empleadas se enferman. Todo ello tiene consecuencias muy negativas en la salud de las mujeres, pues el temor a que las despidan por estar enfermas muchas veces las lleva a ocultar su mal estado de salud, a resistir y aguantar constantemente (Castillo y Mazarrasa, 2001). ${ }^{15}$

Cabe mencionar también el desajuste que existe entre el nivel de formación y la experiencia laboral previa de muchas de estas mujeres, y el trabajo que desempeñan en el estado español, que como hemos dicho está relegado fundamentalmente al servicio doméstico. Esto provoca en las mujeres que cuentan con un alto nivel de formación y calificación un continuo sentimiento de frustración. El principal problema que encuentran las inmigrantes es que no pueden homologar sus estudios: las materias son diferentes y no hay una normativa respecto a las homologaciones, por lo que a pesar de poseer estudios superiores no pueden obtener el reconocimiento de éstos. Mientras en sus países son profesionales, en el estado español deben desempeñar tareas que están muy por debajo de su calificación (UGT, 2001).

Soy licenciada en geografía y ecología por la Universidad de San Petersburgo; estudié hasta los 25 años en la Universidad y no hice más cursos

${ }^{15} \mathrm{Al}$ miedo a ser despedidas hay que añadir su falta de conocimientos en torno a los servicios de salud a los que tienen derecho, y en el caso de las mujeres africanas se une su temor al rechazo social, y la vergüenza que sufren cuando las atiende un hombre. 
porque en mi país ya se supone que estás preparada para trabajar, ya eres especialista cuando sales de la Universidad [Georgeta, inmigrante rusa].

En Bolivia yo trabajaba en una empresa de secretaria ejecutiva, lo hice durante 12 años. Me salí porque me aumentaban el trabajo y no me aumentaban el sueldo. Yo tenía una hora de mi casa al trabajo y gastaba mucho en transporte y comida, entonces no me quedaba nada de sueldo y entonces decidí venirme para acá [Marta Luz, inmigrante boliviana].

Otras dificultades que enfrentan las mujeres inmigrantes en la sociedad de acogida tienen que ver con la regulación de sus "papeles", la reagrupación de su familia, el acceso a una vivienda digna, la participación en los derechos sociales, etc. Todos estos aspectos forman parte de su proceso de integración social y del ejercicio de su ciudadanía.

La regulación de "sus papeles" es de vital importancia para ellas, sobre todo en los primeros años de estancia en el país. La única vía para obtener la documentación pertinente es aceptar una oferta de trabajo, la cual les da acceso a la autorización para trabajar en el estado español y regularizar su situación administrativa. ${ }^{16} \mathrm{El}$ acceso a un contrato de trabajo supone también la inscripción y alta en la Seguridad Social, lo cual conlleva una serie de importantes derechos como asistencia sanitaria gratuita para la trabajadora y su familia, y prestaciones económicas en los casos de: baja en caso de enfermedad de la trabajadora, subsidio de desempleo, incapacidad total, jubilación, y viudez y orfandad (Zabala, 2004). En función de todo esto se entiende que en muchas ocasiones estas mujeres acepten condiciones de trabajo pésimas con el propósito de conseguir los documentos (Colectivo IOE, 2001).

Respecto a la reagrupación familiar, las mujeres que han llegado al país por este cauce dependen en lo administrativo de sus maridos, y sólo podrán obtener un permiso independiente de su cónyuge si obtienen una autorización para $\operatorname{trabajar}^{17}$ o en el caso de que sean

${ }^{16}$ Las mujeres que tienen los papeles en regla disfrutan de unos derechos muy limitados que se sitúan muy por debajo de los que corresponden a la población autóctona, y están sujetos a la renovación de dichos papeles; los inmigrantes quedan así excluidos de derechos como el acceso a la función pública o el derecho a votar. En este sentido Casal y Mestre (2002) observan que la Ley de Extranjería representa la creación jurídica de la diferencia en el acceso a derechos políticos y sociales; diseña una ciudadanía limitada para los inmigrantes.

${ }^{17}$ El permiso de residencia que les otorga la reagrupación familiar no les concede el derecho a trabajar hasta pasados dos años, con lo cual viven una situación de depen- 
víctimas de violencia doméstica, desde el momento en que se dicte una orden de protección a la mujer (Serra, 2001)..$^{18}$ Además, las mujeres solas encuentran muchas trabas administrativas cuando pretenden llevar a sus hijos/as al país de acogida, ya que los trámites son muy lentos y están sujetos a la valoración que hacen los consulados de sus países de las solicitudes de visado.

Otro de los factores que dificultan la integración social de las mujeres inmigrantes en el estado español es el no tener acceso a una vivienda digna. Los bajos sueldos que perciben, su situación irregular y el que tengan que ahorrar para enviar remesas a sus familiares, conduce a la mayoría de ellas a vivir en barrios donde las casas se encuentran muy deterioradas. ${ }^{19}$ Estos barrios albergan a un alto porcentaje de población inmigrante, lo que contribuye a que sean estigmatizados por la población autóctona y catalogados como barrios marginales y peligrosos. A todo esto hay que unir el rechazo de muchos/as propietarios/as a alquilar viviendas a inmigrantes ${ }^{20}$ y los problemas que está ocasionando la aplicación de la Ley de Extranjería L.O. 14/2003 del 20 de noviembre, la cual establece el libre acceso de la policía a los datos registrados en los censos de empadronamiento de inmigrantes. Esto ha provocado que muchos inmigrantes dejen de empadronarse, aumentando así sus dificultades de acceso a la vivienda, ya que la mayoría de las inmobiliarias exige las nóminas o el certificado de empadronamiento para elaborar un contrato de alquiler.

Finalmente, es importante destacar el papel que desempeñan las mujeres inmigrantes en los procesos de integración sociocultural, ya que ejercen la función de "puentes" entre las dos culturas, pues son

dencia económica respecto a sus maridos. Por otro lado, es muy complicado para las mujeres acceder legalmente al estado español para trabajar con un contrato previo a la llegada al país, debido a las características específicas de los sectores para los que se les demanda (Casal, 2004).

${ }^{18}$ La ley establece que las mujeres que llegan por reagrupación familiar tienen un permiso de residencia ligado al de su marido y deben demostrar una convivencia en España de dos años para que se les otorgue un permiso de residencia independiente; esto hace que en muchos casos ellas "no puedan" divorciarse a pesar de sufrir, por ejemplo, malos tratos (Amnistía Internacional, 2003).

${ }^{19}$ En un artículo publicado en el periódico IDEAL de Granada, el 25 de enero de 2004, se informaba que unas 5000 personas inmigrantes residentes en esta ciudad viven en casas con alquileres desorbitados -de hasta 400 euros al mes- para las condiciones que ofrecen (ventanas rotas, goteras y ausencia de calefacción) y las características de los barrios periféricos donde están ubicados, Zona Norte y Zaidín.

${ }^{20}$ Una prueba de esto es el hecho de que en Málaga, la asociación Málaga Acoge, con un programa muy activo de búsqueda de vivienda para inmigrantes, no haya podido alquilar más que nueve departamentos en el año 2003 (Pernía, 2003). 
portadoras de los valores y las costumbres de su país de origen, e intentan al mismo tiempo facilitar su adaptación y la de su familia a las pautas de comportamiento del país de acogida. Esto supone un esfuerzo y una búsqueda de estrategias de adaptación cotidianas, estrategias que buscan también la adaptación de su situación anímica, caracterizada en muchas ocasiones por la tristeza de no estar junto a los suyos, por la soledad o por el futuro incierto.

¿Volver a Colombia?, por ahora no. Hablo con mis hermanas y lloramos por si no nos volvemos a ver, yo les mando mensualmente una cantidad de dinero para ellos; la única esperanza que tienen soy yo, no les puedo fallar [Helga, inmigrante colombiana].

Ya no tengo ni papá ni mamá, somos todos hermanos, mantengo contacto con mis hermanos cada domingo, hablo con ellos por teléfono. Pero ellos nunca han sabido cómo me va la situación acá, ni del trabajo, ni nada. No se lo quiero decir porque me dirían: ¿qué haces allá?, mejor vente [Laura, inmigrante mexicana].

Asimismo, al ser ellas las portadoras de la cultura de su país de origen, ${ }^{21}$ son en ocasiones ellas, sus cuerpos, los que reciben el rechazo hacia esta cultura, sobre todo cuando proceden de países musulmanes; un ejemplo de ello es la negativa de algunas familias españolas a contratar mujeres para el servicio doméstico que lleven pañuelo, o toda la polémica suscitada en Francia por la aprobación de la ley que prohíbe a las niñas asistir al colegio con el velo, por considerarlo un símbolo religioso, lo cual se contradice con el carácter laico de la escuela francesa. El debate en torno a esta ley ha durado bastante tiempo y se han escuchado al respecto muchas voces encontradas procedentes de diferentes sectores de la sociedad; no obstante, en pocas ocasiones se ha pedido la opinión de las propias afectadas (Zabala, 2004). ${ }^{22}$

${ }^{21} \mathrm{Al}$ respecto observa Sophie Bessis (2004) que el problema de muchas religiones, y el del Islam particularmente, es que obliga sólo a las mujeres a llevar los signos identitarios de la comunidad, en este caso el velo; los hombres no llevan ningún signo identitario.

${ }^{22}$ Según Begoña Zabala (2004) más allá del debate en torno "a velo sí o velo no", habría que analizar los efectos de esta ley en las mujeres, analizar la cantidad de niñas que viven situaciones cotidianas de agresión en los guetos en que las ha recluido la sociedad francesa, están siendo escolarizadas en colegios particulares religiosos, o en las propias mezquitas, relegándolas así a un espacio privado, y en muchas ocasiones se les educa conforme a un patrón de sumisión. Amelia Valcárcel (2004) considera que el problema que subyace en todos estos debates es la integración real de las mujeres inmigrantes; el problema no es el velo, sino lo que hay detrás del velo, el significado que 
Por otro lado, es importante señalar el fenómeno de la sustitución que se está produciendo en los lugares de origen de estas mujeres, al que se ha venido llamando la cadena transnacional de cuidados, y la configuración de los hogares transnacionales. Según esto muchas de las mujeres que emigran al estado español a realizar labores de cuidados en sustitución de las madres españolas, a su vez dejan a sus hijas/os en sus países de origen, la mayoría de las veces al cuidado de otras mujeres de su propia familia. Esto da lugar a una cadena de mujeres que, pasando por encima de las fronteras del mundo, crean redes de cuidados al insertarse en ellas en diferentes posiciones (Huarte, citada por Zabala, 2004).

Como hemos visto, son muchos los problemas que tienen que enfrentar las mujeres inmigrantes en su proyecto migratorio; así, se les niega el ejercicio de la ciudadanía en el país de acogida al no tener su documentación en regla o depender de una oferta de trabajo para poder regularizar su situación y la de sus hijos/as. ${ }^{23}$ Casi la única oportunidad de inserción laboral que se les ofrece, cualquiera que sea su formación académica, es el servicio doméstico. A todo esto hay que unir la dificultad de acceder a una vivienda digna y los estigmas sexistas y racistas que las degradan al considerarlas meros "objetos sexuales", que les atribuyen un valor inferior o que las ven en el papel de víctimas o dependientes de sus maridos. Todo ello inserta a estas mujeres en un marasmo de exclusión social del que difícilmente pueden salir. ${ }^{24}$

No obstante, ante esta situación cada mujer desarrolla su propia estrategia de supervivencia en la sociedad de acogida, ${ }^{25}$ no desde el

tiene el velo, que en cierto modo se percibe como una resistencia a integrarse a la cultura de acogida.

${ }^{23}$ La consecución de estos papeles y por tanto la regularización de su situación administrativa sólo les da acceso a una ciudadanía de segunda categoría, pues la ley no acepta la igualdad de derechos de los inmigrantes y los españoles.

${ }^{24}$ Es necesario señalar que aunque la Ley de Extranjería se aplica por igual a todas las mujeres inmigrantes, los niveles de adaptación y aceptación por parte de la sociedad de acogida son mayores cuando hablamos de mujeres procedentes de América Latina y Europa del Este, tal vez debido a que tienen una mayor cercanía cultural, a que hablan el mismo idioma o a que su aspecto físico es parecido (es decir, piel blanca), y menores cuando hablamos de mujeres procedentes de países musulmanes, quienes encuentran más dificultades en la sociedad de acogida. Este fenómeno de mayor rechazo a las musulmanas se ha incrementado a partir de los atentados del 11 de marzo en Madrid.

${ }^{25}$ Una de las estrategias que utilizan las mujeres inmigrantes es insertarse en redes de apoyo entre compatriotas. Se ayudan en la búsqueda de empleo, en el cuidado de las/os hijas/os o en el ámbito afectivo. Estas redes de apoyo desempeñan un papel muy importante en la decisión de emigrar de estas mujeres y varían según los países de procedencia. La red conformada por mujeres dominicanas es una de las más consolidadas actualmente en el país. Por otro lado, estas redes desempeñan una doble función: son un apoyo para las recién llegadas pero a la par ejercen funciones de control sobre ellas 
papel de víctima sino como protagonista de un horizonte de vida que plasma en una diversidad de trayectorias y proyectos. Son mujeres con los perfiles más heterogéneos, ya que a pesar de los problemas comunes que comparten y los estereotipos y clichés que las igualan, son muchas y diversas. Son mujeres valientes que viven dentro de un contexto de desigualdad y discriminación estructural y que luchan por ser reconocidas como ciudadanas de pleno derecho, sujetos con voz propia en busca de un futuro mejor para sí mismas y sus familias.

Tengo ganas de progresar y aprender por mí y por mis hijos y eso repercutirá en la sociedad que me rodea; creo que eso influirá en algún momento. A mí este país me permite trabajar dignamente y vivir tranquila [Carolina, inmigrante argentina].

Un deseo para las mujeres inmigrantes es que sean fuertes, que tiren siempre para adelante, que miren por ellas mismas, no sólo por lo que dejaron detrás, que luchen y que no se dejen pisar por nadie [Laura, inmigrante mexicana].

\section{Bibliografía}

Amnistía Internacional (2003), "Denuncia de la indefensión de las sin papeles maltratadas", La Vanguardia, 11 de julio, p. 35.

Bessis, Sophie (2004), "La polémica sobre el velo en Francia: contenido y consecuencias", conferencia impartida en las Jornadas La Ley contra el Uso de Signos Religiosos en la Escuela Pública Francesa. Disponible en: http://www.comadresfeministas.com/velo-bessis.htm.

Carrasquilla, María Claudia (2004), "Proyectos migratorios: por la exploración de un sueño", Informe: Entre el Magreb y España, voces y miradas de mujeres, Madrid, ACSUR/Las Segovias.

Carrasquilla, María Claudia y Pellicer, Carmen (2004), "Lugares de ida y vuelta", Informe: Entre el Magreb y España, voces y miradas de mujeres, Madrid, ACSUR/Las Segovias.

Casal, Marta (2004a), "Género y migraciones", Informe: Entre el Magreb y España, voces y miradas de mujeres, Madrid, ACSUR/Las Segovias.

(2004b), "Mirándonos: un contexto poco favorable para la integración", Informe: Entre el Magreb y España, voces y miradas de mujeres, Madrid, ACSUR/ Las Segovias.

en cuanto a la limitación de sus movimientos y a la reproducción de los valores tradicionales de la sociedad de origen. 
Casal, R. y M. Mestre (2002), "Migraciones femeninas", en J. de Lucas y F. Torres, Inmigrantes: ¿Cómo los tenemos? Algunos desafios y (malas) respuestas, Madrid, Talasa.

Castillo, Susana y Lucía Mazarrasa (2001), "Salud y trabajo: una relación problemática en los discursos de las mujeres inmigrantes”, Ofrim/Suplementos, junio, pp. 101-111.

Colectivo IOE (2001), "Aportaciones de las mujeres inmigrantes procedentes del Tercer Mundo", Ofrim/ Suplementos, diciembre, pp. 37-55.

(1998), "Mujeres migrantes en España. Proyectos migratorios y trayectorias de género", Ofrim/ Suplementos, diciembre, pp. 12-37.

García-Cano, María (2000), Migración y género. El caso de la comunidad marroquí en la ciudad de Málaga, Málaga, CEDMA.

García Castaño, Javier (2000), “¿A qué nos referimos cuando hablamos de interculturalidad?”, en Luis Pernía et al. (eds.), Inmigrantes, Málaga, CEDMA, pp. 113-126.

Gregorio, Carmen (1998), Migración femenina. Su impacto en las relaciones de género, Madrid, Narcea.

Juliano, Dolores (2003), "La inmigración sospechosa y las mujeres globalizadas", en Carmen Gregorio y Belén Agrela (eds.), Mujeres de un solo mundo: globalización y multiculturalismo, Granada, Universidad de Granada (Feminae).

- (2000), "Mujeres estructuralmente viajeras: estereotipos y estrategias", Papers, núm. 60, Universidad Autónoma de Barcelona, pp. 381-389.

Martín, Emma (2002), "Inmigración e interculturalismo: género e inmigración”, El Clariol, núm. 7, Confederación de STES.

MIR (2002), Anuario estadístico de extranjería 2002, Madrid, Ministerio de Interior.

Pernía, Luis (2003), "Educar la mirada al hilo de la invisibilidad", Revista de Sur a Sur, núm. 28, España, CEDMA/ASPA.

Serra, Inmaculada (2001), "Inmigración femenina, diversidad cultural y trabajo”, en María Ángeles Durán, Inmaculada Serra y Rebeca Torada, Mujer y trabajo: problemática actual, Valencia, Germania.

UGT (2001), Mujeres inmigrantes: factores de exclusión e inserción en una sociedad multiétnica, la situación en España, Unión General de Trabajadores. Disponible en: http:/ / www.ugt.es/inmigración/ mujerinmi.htm.

Valcárcel, Amelia (2004), "La polémica sobre el velo en Francia: contenido y consecuencias", conferencia impartida en las Jornadas La Ley contra el Uso de Signos Religiosos en la Escuela Pública Francesa. Disponible en: http:/ / www.comadresfeministas.com/velo-bessis.htm.

Venegas, Paki (2004), Guía didáctica. Voces de mujeres inmigrantes: La educación intercultural desde una perspectiva de género, Granada, Fondo Social Europeo y Federación Andalucía.

Zabala, Begoña (2004), "Mujeres inmigrantes: algunas consideraciones desde el feminismo”, Revista Rebelión. Disponible en: http:/ /www.rebelion.org/ noticia.php?id=9247. 